\title{
Educational Equity and Educational Informatization New Thinking Based on the Background of "Epidemic"
}

\author{
Lili Tian ${ }^{1}$, Mingjing Dai ${ }^{1 *}$ \\ ${ }^{1}$ Cardiff University, The School of Social Science, Cardiff, CF24 4HJ, Wales, U.K. \\ ${ }^{1}$ Southwest University, The School of Agronomy and Biotechnology, Chongqing, 400700, China \\ *Corresponding author. Email: 1659928168@qq.com
}

\begin{abstract}
In recent years, with the introduction of various policies and the gradual improvement of basic measures for educational informatization, educational informatization has a huge impact on educational fairness both positively and negatively. Affected by the COVID-19 pandemic, more than $90 \%$ of world's learners have been affected as the regular learning approaches are not appropriate during this time [1]. Lots of major education platforms used Internet media to carry out online teaching and educational informatization has been forced to be realized in a large scope. Educational equity under this new background is also facing new opportunities and challenges. This study aims to analyze the inhibitory effects of online education on educational equity from the perspectives of technology, teachers, students and families. In addition, the author provides an actionable solution to further alleviate the inequity of education in remote areas and realize the equal distribution of educational resources.. In conclusion, this study confirms that the solution to the problem of educational inequity needs to be solved jointly from the social, government and individual
\end{abstract}

Keywords: Online Education; Educational Informatization; COVID-19 pandemic; Educational Equity; Educational Fairness.

\section{INTRODUCTION}

Educational equity is an important part of social equity and an important indicator for measuring the development of education in China. The combination of information technology and education is an important way to promote the sharing of educational resources and reduce the educational imbalance between urban and rural areas in China. In 2015, the online learning report of OECD showed that with the rapid development of global informatization, children of bottom families in most countries have more access to the Internet, but the education gap between students has not been narrowed, and the "new digital divide" is gradually expanding [2]. China's online education market scale is growing rapidly with showing that China's online education market scale reached 404.1 billion yuan/RMB in 2019 and 453.8 billion yuan/RMB in 2020. In terms of user growth, the number of online education users in China reached 261 million in 2019 and 309 million in 2020 [3].
On January 29, 2020, due to the impact of the COVID-19 epidemic, the Ministry of Education proposed to use the network platform to achieve "classes suspended but learning continues" [4]. With schools across the country beginning classes online, it is expected that 300 million students would flood into the online teaching platforms, which has brought a great challenge to the informatization of education. Under the promotion of the "epidemic" situation, education informatization has been forced to be realized in a large scope, however, not all schools, families and students from all over China can take good advantage of online education platforms. During the COVID-19 pandemic, it has even become more difficult for rural education departments to maintain basic education, not to mention achieving educational equity. This research expounds the process of online education exacerbating educational inequity in rural areas from three aspects. Firstly, because the network infrastructure in rural areas is imperfect and backward, online education in rural areas cannot be carried out successfully. Secondly, the perspective of analysis is transferred from above objective factors to the 
role of school teachers. Teachers are a very important part of teaching activities. However, by comparing the interaction and teaching quality of rural and urban teachers, it can be found that rural teachers are slightly inadequate and unable to create high-quality classes. This situation has further deepened the education gap between rural and urban areas Finally, starting from the students' own families, the low education level of parents or guardians, and the lack of subjective will to investing and creating a family atmosphere will have a negative impact on students' home learning in rural areas.

\section{ANALYSIS OF THE FACTORS AFFECTING THE UNFAIRNESS OF EDUCATION IN URBAN AND RURAL AREAS}

\subsection{Backward internet infrastructure in rural areas}

In 2018 , there were still 101,400 small-scale schools in rural areas, accounting for $38.52 \%$ of the total number of rural primary schools [5]. Theoretically speaking, large-scale schools and small-scale schools have their advantages and disadvantages. However, Small-scale schools in rural areas are often forced to be established due to economic backwardness and low population density. Therefore, the advantages of small-scale schools are not reflected in rural areas. Moreover, in practice, due to the lack of mining the advantages of small-scale schools, the educational advantages of rural small-scale schools have not been highlighted. On the contrary, their disadvantages are more and more obvious [6]. It is undeniable that the role of these small-scale schools in facilitating students in remote and poor areas to enter school nearby, and strengthening the revitalization of rural education cannot be underestimated. However, according to our field survey in the central and western regions in China, limited by the level of economic development, many students are absent from online classes due to Internet equipment or network signals [7]. At present, the poor network environment and the lack of information infrastructure are still the two major obstacles to the development of online education in rural areas [8]. Although China's Internet penetration rate is gradually rising, according to the data of The 45th Statistical Report on Internet Development in China reported by CNNIC [9]. As of March 2020, the Internet penetration rate in China's urban areas was $76.5 \%$, while that in rural areas was only $46.2 \%$ [9]. There is evidence to show that, compared with urban students, it is more difficult for rural students to access internet resources during the epidemic. If small-scale schools in rural areas want to realize educational informatization, the investment in the construction of infrastructure and the creation of network environment is huge. However, with the gradual reduction of the number of students in rural small-scale schools, there is a wide gap between input and output, which will directly affect the willingness and determination of local governments to invest in information construction. Although online education does not require high-end equipment and only needs mobile phones or computers, students in rural areas will lose the opportunity to receive online education due to the backward overall economic level and the geographical restrictions without signal coverage and infrastructure. Especially during the period of COVID19 , offline education has been completely stopped, which will undoubtedly lead to difficulties in teaching tasks in rural areas and further aggravates educational inequity.

\subsection{The low interaction index and lack of informational literacy of teachers in rural areas}

Online education is quite different from traditional full-time education, which is mainly reflected in the nonsynchronization between teachers and students in time and space. Conducting online courses requires teachers to master the knowledge and ability that are different from traditional ones, since teachers are the implementers of online education and one of the most important factors for the assurance of education quality [10]. It is a difficult problem for teachers to transfer the advantages of traditional teaching to the teaching process based on the network. Teachers need to change their teaching methodologies from "face-to-face" to online teaching, searching for proper ways to interact with their students and leading a good class [11]. In the knowledge economy and information age, facing the explosive growth of network knowledge and constantly updated digital technology, teachers' original professional knowledge and skills cannot meet their own needs for survival and development. Online education requires teachers to have information literacy, strong integration ability, and highly reflective practical ability. From the perspective of discipline, compared with other disciplines, the interaction index of information technology course is the highest, that is, the interaction forms are the most abundant. The data proves that the teachers of information technology courses use interactive technology best. This also shows that the degree of interaction of online education is directly related to the information literacy of teachers [12]. There are few teachers and educational staff who understand network technology and have excellent teaching quality, which has greatly affected the successful promotion from traditional teaching mode to network teaching during the epidemic. A national survey shows that the teacherstudent interaction index has a significant positive impact on the interaction effect. However, in the sample, through ANOVA analysis, it is found that teachers in different regions have a significant impact on the interaction index $(\mathrm{F}=18.984, \mathrm{P}=0.00)$, and there are different differences in the interaction index in different regions. The interaction index of county, township, and rural areas is 
significantly lower than that of municipalities and provincial capitals (figure 1) [12]. Due to the sudden outbreak of the epidemic, teachers in remote areas are not fully prepared either technically or mentally, which leads to the disorder of online education in rural areas. This situation further aggravates the phenomenon of educational inequity between regions.

\section{Teacher interaction index in different areas}

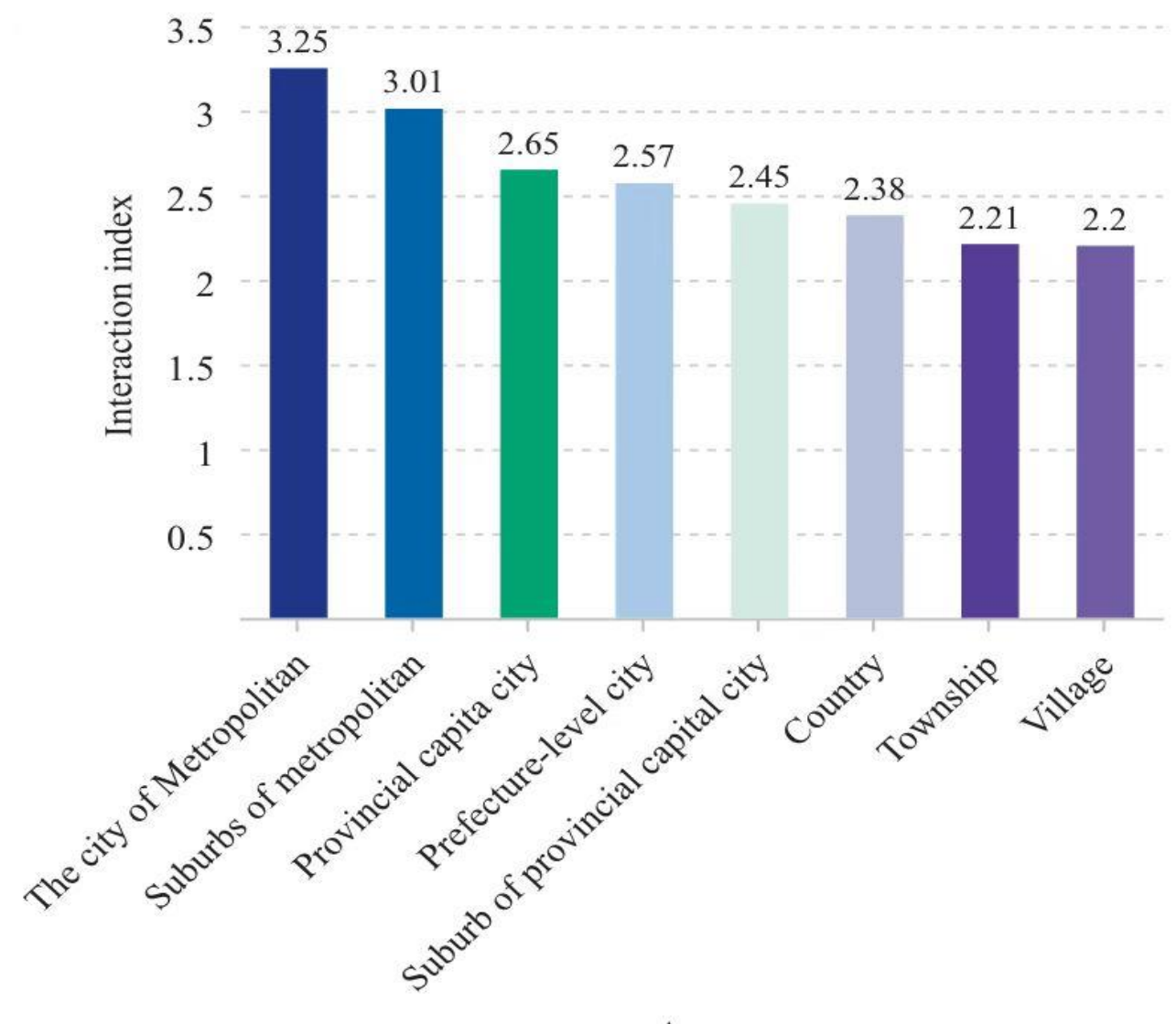

Areas

Figure 1. Teacher interaction index in different areas

\subsection{Inhibitory effect of family factor on online education}

This global epidemic has not only had an impact on the economy and politics, but also changed the concept and mode of education. Although online education is an emergency measure launched by all countries during the period of the COVID-19 pandemic, online education will become a trend along with the construction of education informatization. Online education, as another way of home learning, disperses students' previous learning environment from a unified campus environment to different family environments, thus amplifying the impact of family environment and atmosphere on students' learning effect. After collecting 150 questionnaires on family learning environment from all over the country, the respondents' awareness of family learning environment planning and design is generally weak, and only $46.67 \%$ of the respondents have the consciousness of designing family learning environment [13]. Secondly, many parents or guardians who are generally older in rural areas lack the ability to form good communication with teachers, which has become a practical problem of online education at home. Homeschool cooperation in the digital era has become a major challenge for online education. In addition to lacking a good place and atmosphere for learning, rural students have to take on responsibilities such as farming and housework. Moreover, the parents or guardians have a low level of education and cannot provide sufficient academic guidance for these students [14].

Furthermore, online education has a higher threshold for family education investment. According to the research of Zou W and Zheng $\mathrm{H}$ [15], the poorer families are, the lower their willingness to invest in human capital. As an exogenous shock, COVID-19 affects the learning of students both in urban and rural areas, but, students from rural areas are more likely to have "learning interruption" because of family factor. Therefore, it is difficult for students from poor families to ensure the hard demand of participating in online education, 
whether in terms of the home environment, willingness, or economic ability.

\section{THE PROMOTION OF EDUCATIONAL INFORMATIZATION TO EDUCATIONAL EQUITY UNDER THE COVID-19 PANDEMIC SITUATION}

\subsection{Smooth operation of network cloud platform}

Before this, the inequity brought by educational informatization to education is mainly reflected in the gap of facilities and networks between rural and urban regions. Although schools in most areas have built multimedia classrooms and carried out information teaching, in remote rural areas, however, the promotion and construction of some infrastructures are limited by the economy and network delivery [16]. Fortunately, under the instruction of "classes suspended but learning continues", online teaching has been carried out in most regions. Students only need a computer or mobile phone to attend class, so they can take a ride on information teaching and narrow the education gap caused by the imbalance of information.

Under the influence of the COVID-19, the surging number of users in network operations is a huge challenge for educational informatization. To ensure the smooth operation of the network platform, the Ministry of Industry and Information Technology has deployed Ali and other technology companies to provide comprehensive technical support, which can be used by 50 million students online simultaneously. Each student only needs a computer or a mobile phone to catch the ride of informatization teaching, which not only guarantees the equity of education for every educated person, but also reduces the education gap caused by the imbalance of information infrastructure between schools, and further promotes the realization of the fairness of education starting point.

\subsection{Open free high-quality course resources}

During the period of COVID-19 pandemic, the state and online education institutions have opened up a variety of free and high-quality education resources, which has greatly promoted the fair allocation of education in course resources. On February 17, the national network cloud platform for primary and secondary schools was officially launched, allowing all regions to choose to use it independently without any charge. In addition, the major educational counseling institutions have also set up free education courses. Among them, the number of applicants for free live classes of Homework Help (an application in China) exceeded 28 million. The "online classroom" function of
Ding Ding Talk is free for use in universities, middle schools as well as primary schools nationwide. At the same time, through WeChat public accounts, major medias also help students to know COVID-19 accurately and develop their sense of social responsibility through "micro" classes such as life education knowledge and heroic deeds in the battle against the "epidemic".

\section{MEASURES TO PROMOTE EDUCATIONAL FAIRNESS IN EDUCATION INFORMATIZATION UNDER THE COVID-19 PANDEMIC SITUATION}

\subsection{Intensify efforts to speed up the construction of educational information-based infrastructure}

Narrowing the difference in information infrastructure between urban and rural areas is the material basis for promoting educational equity. During the period of epidemic prevention, the government should carry out statistics in advance for areas without network signals, and organize and arrange some nonnetwork platforms learning. For left-behind children, schools should organize specialists to provide one-onone counseling. Some major telecommunication companies could offer some assistant within their ability, such as increasing the construction of networks in rural areas and providing some preferential rates for poor families in need. All sectors of society should work together to create a great study atmosphere and satisfy the basic need for online study to guarantee every students' online study.

\subsection{Training in advance to improve teachers' information technology}

One or more national online training courses for teachers should be conducted immediately before the start of online education. The educational informatization under this epidemic of COVID-19 has presented an informative teaching mode, different from traditional ones. That is, students learn at home, teachers teach remotely, and teachers and students interact remotely. Only by mastering this new teaching method well can teachers help students better. In addition, responsible personnel need to pay special attention to the training of elder teachers and give them full guidance.

\subsection{Strengthen parents' awareness of education}

All the departments and schools need to expand the publicity of educational informatization through some medias and give detailed information about online education in order to let both parents and students form 
positive attitudes towards online study. Also, teachers are supposed to encourage parents to participate in the process of online study. Parents themselves should also be responsibilities for students' study, help supervise students' study and cooperate with teachers actively to complete the online study. For some families whose parents lack the ability to help their children, teachers need to pay more attention to their study and mental health.

\section{CONCLUSION}

The findings and analysis of this essay have suggested that students in rural areas cannot access highquality educational resources as same as the children in urban areas due to technology, teachers, and family factors. Although online education has been regarded as an effective means to break the regional monopoly of educational resources and enhance educational fairness, this study provides new insights and solutions for the development of online education. This finding has opened up new and interesting ideas in the field of educational inequity that requires further study. This paper is only a preliminary study on the impact of the COVID-19 epidemic on education equity, and there are still some deficiencies. For example, because the total number of samples of the data adopted this time is not large enough, and the age of the samples is mainly concentrated in the two stages of high school and junior high school, the coverage is not wide enough. Next, we hope to continue our research in the field of educational inequity, such as the long-term impact on students' future career choices under the impact of educational inequity, in order to find the causes of educational inequity from different angles, alleviate the phenomenon of educational inequity in remote and poor areas, narrow the educational gap and further improve national quality.

\section{REFERENCE}

[1] Sharma, A., and Alvi, I. (2021) Evaluating pre and post COVID 19 learning: An empirical study of learners' perception in higher education. Education and information technologies, pp. 1-18.

[2] OECD. 2015. Student, computers and learning: making the connection $[\mathrm{M}]$. Paris: OECD Publishing.

[3] Science China. (2020) China's online education market will reach 453.8 billion, and the industry is developing well [online] Available at: http://science.china.com.cn/2020-

02/17/content_41061743.htm [Accessed 27 August 2021]

[4] Ministry of Education of the People's Republic of China. (2020) Ministry of Education: use the network platform to realize "class suspended but learning continues" [online]. Available at: http://www.moe.gov.cn/jyb_xwfb/gzdt_gzdt/s5987 /202001/t20200129_416993.html [Accessed 29 August 2021]

[5] Mu S. (2019) Deepening and reconstruction: mobile learning and online education. Bei Jing: Higher Education Press.

[6] Qing, Y Y. (2010) Dilemma and solution of educational quality in rural small-scale schools. Journal of The Chinese Society of Education, pp. 912.

[7] Xu, Y Y. (2020) Let all students enjoy the convenience of online class. People's daily. People's Daily [online], 26 March 2020. Available at: http://m.people.cn/n4/2020/0326/c25-

13815184.html?from=timeline [Accessed 7 July 2021]

[8] Fu, W D. Zhou, H Y. (2020) Challenges brought by COVID-19 to China's online education and countermeasures. Journal of Hubei Normal University, 22(2), pp. 3-5.

[9] Cyberspace Administration of China. (2020) The 45th Chins Statistical Report on Internet Development [online]. Available at: http://www.cac.gov.cn/202004/27/c_1589535470378587.htm [Accessed 2 August 2021]

[10] Abrami, P C. et al. (2004) How Does Distance Education Compare With Classroom Instruction? A Meta-Analysis of the Empirical Literature. Review of Educational Research, 74(3), pp. 379-439.

[11] Casacchia, M. et al. (2021) Distance education during COVID 19: an Italian survey on the university teachers 'perspectives and their emotional conditions. BMC Medical Education, 21(1), pp. 335.

[12] GMW. (2020) An interactive study on online education in primary school and middle school in COVID-19 [online]. Available at: https://edu.gmw.cn/2020-

04/02/content_33708443.htm [Accessed 19 August 2021]

[13] Wang, Y W., et al. (2020) How can family education be possible: from study, private school to Smart Family Learning Environment. Further and Development, pp. 33-41

[14] Liu, J M. Yang, J H. (2007) Pay attention to the educational equity of poor children. Journal of Huazhong Normal University, 46(2), pp. 123-125.

[15] Zou, W., and Zheng, H. (2014) Why children from poor families don't read: risk, intergenerational 
transmission of human capital and poverty trap. Economic Perspectives, pp. 16-31.

[16] Yang, Z C. Li, F. (2014) Significance and Countermeasures of promoting educational informatization for educational equity. Journal of Teaching and Management, pp. 48-50. 